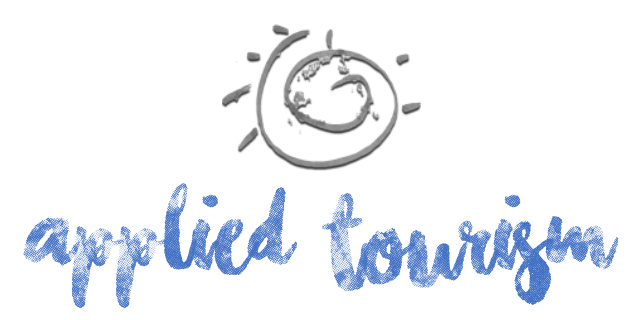

Volume 2, número 2, 2017, p. 24-42

\title{
A ATIVIDADE PRÁTICA NA FORMAÇÃO DOS ACADÊMICOS DE HOSPITALIDADE: experiência dos colaboradores voluntários na organização do VI Congresso Internacional de Turismo do Extremo Sul (Cites)
}

\author{
Maria do Carmo Schwab Brandão \\ Licenciada em História e Tecnóloga em Eventos \\ Universidade Federal do Rio Grande \\ mariaschwab@furg.br \\ Alice Leoti Silva \\ Mestra em Memória Social e Patrimônio Cultural \\ Universidade Federal do Pampa (UNIPAMPA) \\ alicesilva@unipampa.edu.br \\ Raphaella Costa Rodrigues \\ Mestra em Turismo e Hotelaria \\ Universidade Federal do Rio Grande \\ raphaellacosta.furg@gmail.com
}

Recebido: 28 de junho, 2017

Aprovado: 28 de agosto, 2017

\section{RESUMO}

O objetivo deste trabalho é analisar a inserção de atividades práticas na formação profissional daqueles que atuarão na área da hospitalidade através da experiência dos voluntários que participaram da organização do VI CITES (Congresso Internacional de Turismo do Extremo Sul). Tal evento foi promovido pelo Laboratório de Planejamento Turístico que integra os cursos de Turismo, Hotelaria e Eventos, realizado na FURG/SVP. Teve como objetivos específicos: verificar o processo de tomada de decisão na organização do evento pelos voluntários; identificar a percepção da atividade como parte da formação profissional; relacionar o processo educativo e a prática profissional. Além da pesquisa bibliográfica, realizou-se um estudo de caso em que foram feitas entrevistas diretas e aplicação de questionários. Os resultados indicaram a importância das atividades práticas na formação profissional, especialmente quando o trade encontra-se em estágio embrionário.

Palavras-chaves: Hospitalidade. Prática Profissional. Formação Profissional. CITES. Santa Vitória do Palmar. 


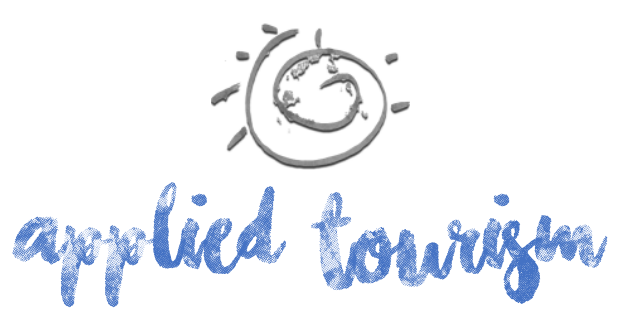

Volume 2, número 2, 2017, p. 24-42

dos seguintes objetivos específicos: verificar como se estabeleceu o processo de tomada de decisão na organização do evento pelos colaboradores; identificar se a atividade foi percebida como parte da formação profissional; e compreender a vinculação entre o processo educativo e a prática profissional.

Neste sentido, para Silva e Miyashiro (2007), organizadores da pesquisa "Turismo e Hospitalidade no Brasil: um estudo sobre os Trabalhadores da Hotelaria", é justamente no campo educacional, da qualificação profissional que se torna essencial intensificar a luta pela educação propedêutica e profissional, gratuita e de qualidade, como direito dos trabalhadores e objeto de negociação com o Estado e empresários.

O eixo central da pesquisa diz respeito ao "ensinar, ao repensar" o processo ensinoaprendizagem, para tanto nos valemos do pensamento de Paulo Freire quando afirma: "ensinar não é transmitir conhecimentos, mas criar as possibilidades para a sua produção ou sua construção" (Freire, 1996). Seguindo o pensamento de Freire, considera-se como requisito fundamental para o processo ensino aprendizado, o respeito aos saberes e o estímulo à curiosidade do educando, a utilização da pesquisa, o respeito à ética e ao diálogo.

O interesse pelo referido estudo é uma continuidade de uma pesquisa realizada anteriormente, que resultou no resumo expandido "Projetos de extensão e a formação do profissional de eventos: um estudo do projeto "Equipe Gestora de Eventos" - FURG/SVP". Na ocasião buscou-se avaliar o impacto gerado pela atuação prática no planejamento e operacionalização em diversos eventos, junto a comunidade acadêmica e a sociedade local, a fim de contribuir para a formação dos alunos do curso de Tecnologia em Eventos. Esta participação permitiu aos componentes da equipe exercitar o conhecimento teórico apreendido na academia. Deste modo, o presente artigo tratará da formação acadêmica de futuros profissionais da área de hospitalidade, além de verificar o desenvolvimento de suas competências através de atividades promovidas pela Instituição de Ensino Superior. 


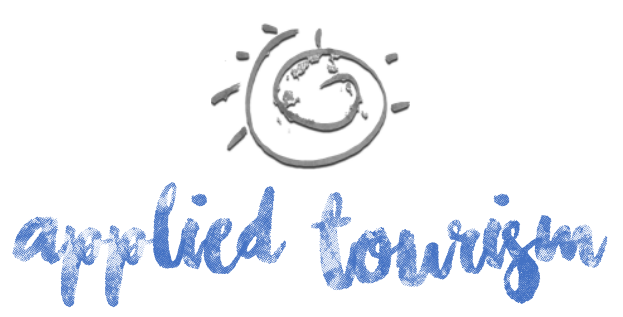

Volume 2, número 2, 2017, p. 24-42

Além disso, para que um colaborador atue de maneira motivada e seja capaz de desempenhar suas atividades com êxito, observa-se a necessidade de dar segurança e autonomia para que este desenvolva habilidades para exercer suas funções de forma plena e motivada. Porém, é essencial que o clima organizacional predisponha destas prerrogativas para que a gestão e operacionalização do evento sejam bem-sucedidas (Griffin \& Neal, 2000).

O elemento humano é primordial para a organização e planejamento de eventos, pois, a atividade exige o emprego de esforços técnicos e recursos materiais para sua realização, além da satisfação do público alvo. Desta forma, para melhor ordenação e produtividade, os eventos podem ser classificados conforme sua tipologia ou modalidade, seu fator gerador, abrangência, etc. (Zanella, 2011).

A profissionalização da educação em eventos permitiu que o mercado de eventos passasse a oferecer distintas possibilidades de carreiras para profissionais da área. Goldblatt (2010) menciona alguns tipos de carreira em eventos, são elas: diretor de atrações, diretor de alimentos e bebidas, gestor de logística, diretor de eventos em cruzeiros, gestor de qualificação em eventos, organizador de eventos para arrecadação de fundos para instituições beneficentes, diretor de festivais, gestor de eventos fitness e de saúde, gestor de eventos turísticos, diretor de eventos acadêmicos e estudantis, entre outros.

Frente à diversidade do mercado de eventos e aproximando para o objeto de estudo, observa-se que um congresso de turismo com abrangência internacional de base científica, segundo Cros e Jolliffe (2014) pode ser enquadrado na categoria "Negócios e Trade". Getz e Page (2016) salientam que na gestão destes eventos, a equipe de produção e elaboração deve focar o planejamento do evento sobre o gerenciamento interno de pessoas e externo referente ao alcance das partes interessadas, buscando agregar valor sobre o evento conforme as necessidades e expectativas do público alvo. 


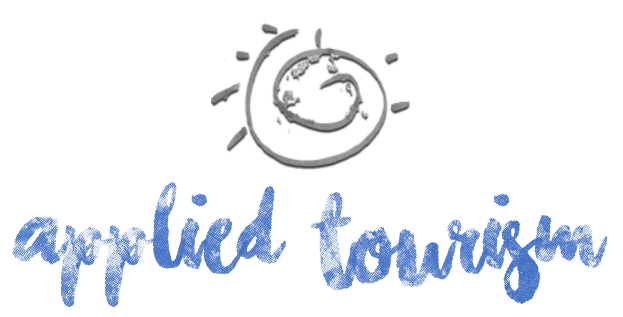

Volume 2, número 2, 2017, p. 24-42

Partindo dos pressupostos apresentados na gestão e operacionalização de eventos, abordarse-á a relevância da reflexão acerca do processo de educação e formação de profissionais aptos para a atuação no mercado de eventos.

\section{Educação e prática profissional}

Acompanhando o grande crescimento econômico do setor de hospitalidade observa-se a crescente preocupação com a formação de gestores e técnicos para atuarem na área. Pensar sobre o processo de formação é imprescindível para se chegar a um profissional capacitado. Parte-se do princípio defendido por Paulo Freire (1996) que entende a prática do ensino não apenas como um método de transferência dos conhecimentos, mas, um meio para criar as possibilidades para a sua produção ou a sua construção, ou seja, para desenvolver competências.

Nesse sentido, entende-se que o processo de formação profissional não se dê apenas na esfera teórica, mas aquele que contemple uma boa parcela de atividades práticas que permitam ao acadêmico construir seus saberes. Segundo Pimenta e Lima (2005, p. 7),

o exercício de qualquer profissão é prático, no sentido de que se trata de aprender a fazer 'algo' ou 'ação'" e, portanto, o aprendizado se dará "a partir da observação, imitação, reprodução e, às vezes, da reelaboração dos modelos existentes na prática (Pimenta \& Lima, 2005, p.7).

Deve-se ainda, mencionar sobre o processo motivacional incidente sobre o indivíduo durante a aprendizagem. Conforme Palacio e López e Nieto, (2006, p. 224), este se integra ao contexto intelectual do indivíduo, e está diretamente relacionado ao grau de habilidade que o sujeito atribui a si mesmo e sobre a capacidade de desenvolver a própria aprendizagem. Ou seja, motivação em superar-se em aprender. Os autores, também, salientam a necessidade do domínio da técnica para a execução de ações e operações próprias da área de atuação. Para tanto nem sempre o desenvolvimento de habilidades é suficiente para solucionar os diferentes problemas com os quais irá se deparar no mercado 


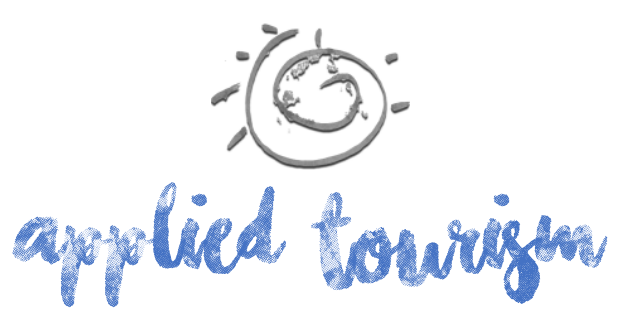

Volume 2, número 2, 2017, p. 24-42

de trabalho (Pimenta \& Lima, 2005, p. 8). Entende-se, pois a relevância da formação acadêmica que busca a maior aproximação possível com a realidade do fazer profissional através de práticas ancoradas no comprometimento e na intencionalidade.

Assim, compreendem-se dois sistemas motivacionais que refletem sobre o indivíduo durante o processo de aprendizagem, são eles: sistema motivacional competitivo e cooperativo. No primeiro, o sujeito se motiva a destacar-se sobre os demais, sendo o êxito pessoal o fator motivador. Enquanto que no caso do sistema de motivação cooperativo, o êxito pessoal é destacado ao mesmo tempo em que se espera ter contribuído com a equipe como um todo. Assim, este é apontado como sistema ideal de motivação entre discentes, devido ao compromisso com o ato de aprender (Palacio \& López \& Nieto, 2006).

As realizações de diferentes atividades práticas são segundo Sônia Maria Guedes Gondim (2002, p. 300):

avaliadas como alternativas para atender à exigência de um perfil multiprofissional e proporcionar a maturidade pessoal e a identidade profissional necessárias para agir em situação de imprevisibilidade, realidade a que estão sujeitas as organizações atuais.

As palavras de Gondim retratam claramente as exigências do perfil esperado do profissional que pretende atuar no setor de hospitalidade justamente por sua imprevisibilidade.

\section{METODOLOGIA}

Esta pesquisa tem como objetivo analisar a importância de atividades práticas no processo de formação acadêmica na área de hospitalidade, realizada por meio de pesquisa bibliográfica e estruturada sobre o estudo do VI CITES. De acordo com Sampieri e Collado e Baptista (2010), caracteriza-se por uma pesquisa qualitativa àquela que permite o aprofundamento no universo de pesquisa, analisando o fenômeno como um todo, aqui delimitado sobre o vasto contexto da formação e a atuação profissional do setor de eventos a partir da experiência prática na organização de um congresso. 


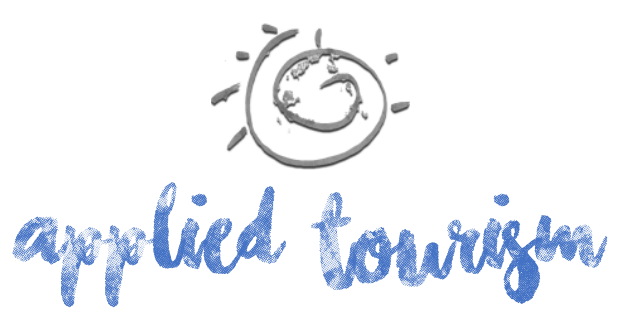

Volume 2, número 2, 2017, p. 24-42

Esta pesquisa se classifica quanto a seus objetivos por uma vertente exploratória que, para Gil (2002), é utilizada para explorar de uma forma geral um fenômeno estudado, permitindo a delimitação do tema. Além de uma vertente descritiva, que para Falcão e Andrade (2002), assegura a descrição do tema pesquisado, ou ainda, conforme Raupp e Beuren (2003), permite ao descrever o fenômeno, traçar relações existentes entre as informações obtidas na etapa exploratória.

Elaborou-se um questionário semiestruturado a fim de viabilizar o reconhecimento das experiências vivenciadas pelos acadêmicos voluntários dos cursos de Bacharelado em Turismo, Hotelaria e Tecnologia em Eventos da Universidade Federal do Rio Grande, que atuaram no VI CITES. Nesse sentido, a organização do evento, elaborou um instrumento para coleta de dados composto por 20 perguntas abertas e fechadas, que buscassem identificar, na prática pedagógica, a vinculação entre ensino e prática profissional. O questionário tratou de questões como: a tomada de decisão na organização de eventos, formação profissional e sua vinculação com teoria e prática.

A condução desta pesquisa e da sistematização metodológica permitiu ao final compreender o processo educativo através da experiência prática profissional estabelecida na organização do VI CITES.

\section{RESULTADOS E DISCUSSÃO DOS DADOS}

\section{Caracterização do objeto de estudo}

O surgimento do Congresso Internacional de Turismo do Extremo Sul - CITES, está diretamente ligado à construção de um campus universitário, em Santa Vitória do Palmar, RS/BRASIL, pela Universidade Federal do Rio Grande (FURG), em parceria com a prefeitura do município, com a criação do curso de Bacharelado em Turismo Binacional. 


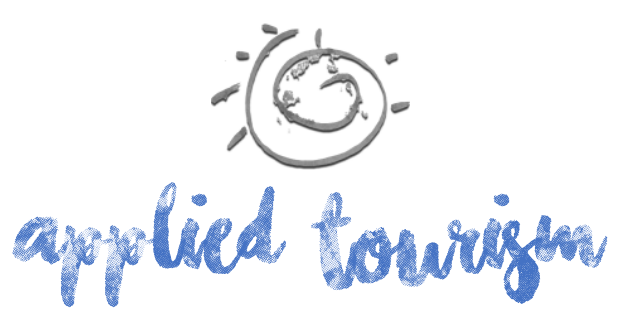

Volume 2, número 2, 2017, p. 24-42

No gráfico 1, é possível verificar a área de atuação durante as etapas de planejamento e execução do VI CITES. Cabe salientar que os discentes tiveram participação em todas as comissões que compuseram o evento em questão.

Gráfico 1: Setores de atuação

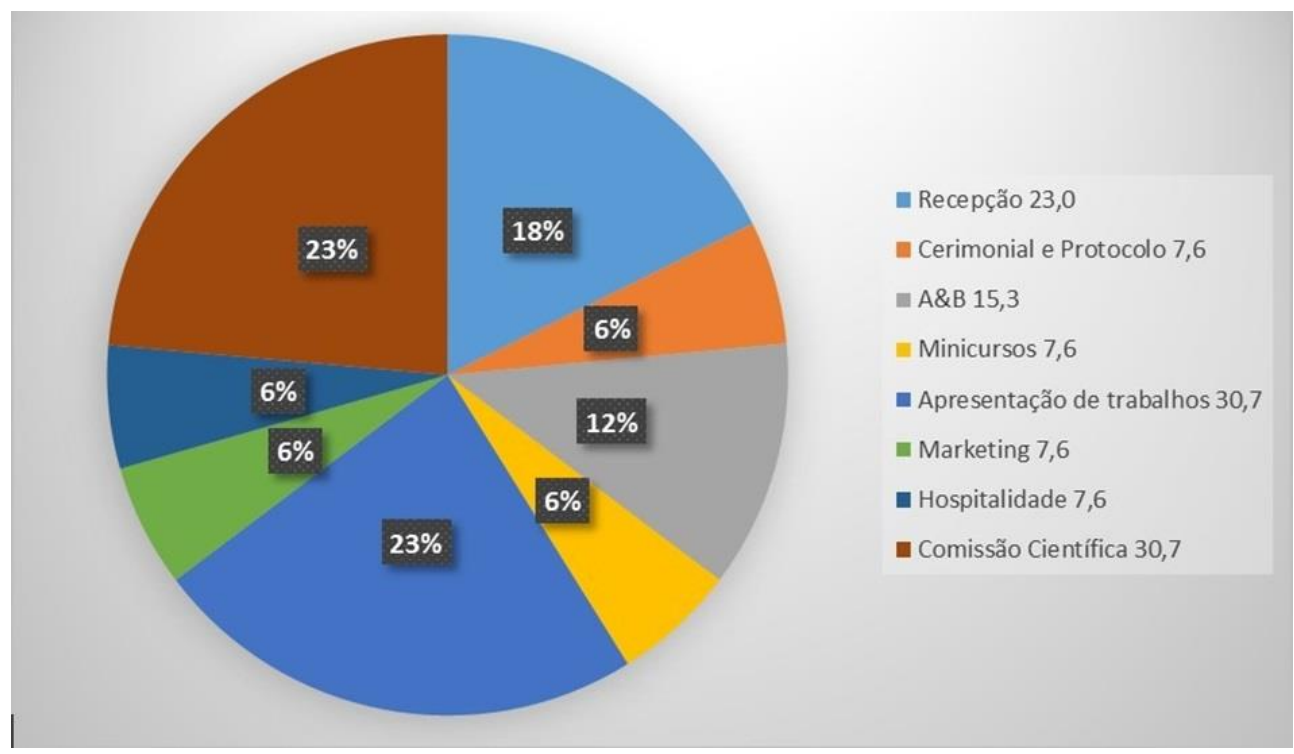

- Cerimonial e Protocolo 7,6

A\&B 15,3

Minicursos 7,6

Apresentação de trabalhos 30,7

Marketing 7,6

Hospitalidade 7,6

- Comissão Científica 30,7

Fonte: autores, 2017.

Perguntou-se aos participantes acerca das motivações pessoais que os levou a desejar integrar a equipe de trabalho. Esta foi uma pergunta aberta, deste modo, lograram-se respostas diversificadas, mas que se reproduziram em diversos respondentes. Pode-se, assim, então mencionar algumas expressões usadas como respostas: busca pelo conhecimento; desafio; trabalho em equipe; oportunidade aprendizado, experiência e crescimento acadêmico; colaboração; interesse pessoal; isenção nas inscrições; e, horas complementares.

No gráfico 2, nota-se que apenas um dos participantes ofereceu-se para compor a equipe organizadora. Outros quatro participantes são integrantes do Programa de Ensino Tutorial (PET) do curso de Bacharelado em Turismo. Os demais tiveram indicação ou convite por parte dos docentes e técnicos. 


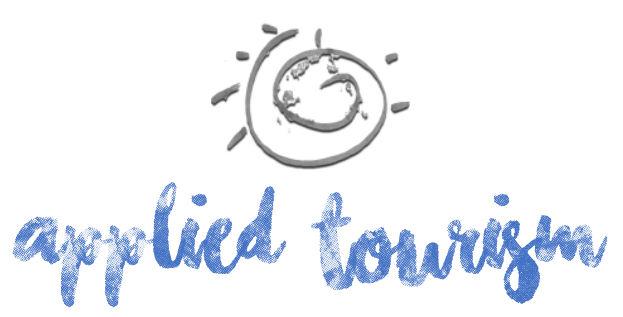

Volume 2, número 2, 2017, p. 24-42

prático, mas tendo como aporte a teoria estudada. Deste modo, relembrando Freire o acadêmico se utiliza dos conhecimentos para produzir as possibilidades.

No entanto, é possível notar também que somente esta prática durante a formação acadêmica não é suficiente para dar suporte e fazer com que o acadêmico se sinta totalmente apto a atuar no mercado de trabalho. Nesse sentido, é imperativo que a relação teoria e prática sejam estimuladas no meio acadêmico a fim de completar a formação do futuro profissional da área de hospitalidade. Assim, o acadêmico terá uma noção mais aproximada do que é o exercício profissional da área na qual elegeu atuar. O estudo demonstra, ainda, as fragilidades do sistema educacional voltado para o setor de hospitalidade.

\section{REFERÊNCIAS}

Abeoc, \& Sebrae. (2014). II Dimensionamento Econômico da Industria de Eventosno Brasil- 2013. Brasília: Expo Editora.

Brasil, Ministério do Turismo. (2010). Turismo de negócios e eventos: orientações básicas. /Ministério do Turismo, Secretaria Nacional de Políticas de Turismo, Departamento de Estruturação, Articulação e Ordenamento Turístico, Coordenação-Geral de Segmentação. 2.ed - Brasília: Ministério do Turismo.

Cros, H., \& Jolliffe, L. (2014). The arts and events. Routledge.

Falcão, E. F., \& Andrade, J. M. (2002). Metodologia para a Mobilização coletiva e individual. João Pessoa: Editora da UFPB, p. 28-97.

Freire, P. (1996). Pedagogia da Autonomia Saberes necessários à prática educativa. São Paulo: Paz e Terra.

Getz, D, \& Page, S. J. (2016). Event studies: Theory, research and policy for planned events. Routledge.

Gil, A. C. (2002). Como elaborar projetos de pesquisa. São Paulo, v. 5, p. 61.

Giacaglia, M. C. (2011). Eventos: como criar, estruturar e captar recursos. São Paulo: Aleph.

Goldblatt, J. (2010). Special events: A new generation and the next frontier. John Wiley \& Sons. 


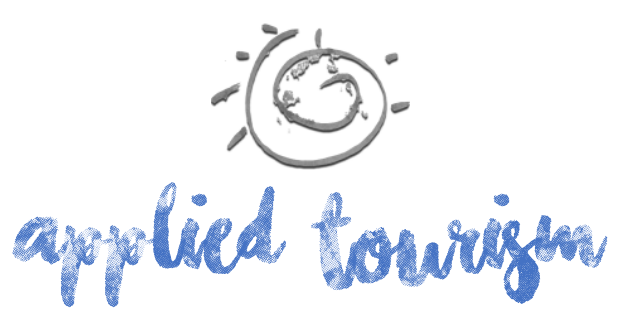

Volume 2, número 2, 2017, p. 24-42

Gondim, S. M. G. (2002). Perfil profissional e mercado de trabalho: relação com a formação acadêmica pela perspectiva de estudantes universitários. Universidade Federal da Bahia: Estudos de Psicologia, Vol. 7(2), p.299-309.

Griffin, M. A., \& Neal, A. (2000). Perceptions of safety at work: a framework for linking safety climate to safety performance, knowledge, and motivation. Journal of occupational bealth psychology, v. 5 , n. 3, p. 347.

Ibge, Coordenação de Contas Nacionais. (2012). Economia do turismo: uma perspectiva macroeconômica 2003-2009 / IBGE - Rio de Janeiro: IBGE.

Palacio, C. R., \& López, G. C. H., \& Nieto, L. A. R. (2006). Qué es la intervención psicopedagógica: definición, principios y componentes. El Ágora USB Medellín-Colombia, v. 6, n. 2, p. 215226.

Pimenta, S. G.; \& Lima, M. S. L. (2005). Estágio e docência: diferentes concepções. Revista Poíesis, v. 3, n. 3, p. 5-24.

Raupp, F. M., \& Beuren, I. M. (2003). Metodologia da pesquisa aplicável às ciências sociais. Como elaborar trabalhos monográficos em contabilidade: teoria e prática, v. 3, p. 76-97.

Sampieri, R. H., \& Collado, C. F., \& Baptista, L. P. (2010). Metodología de la investigación. México, DF.

Silva, A. L., \& Miyashiro, R. (org.). (2007). Turismo e bospitalidade no Brasil: um estudo sobre os trabalhadores da hotelaria. São Paulo: CUT.

Zanella, L. C. (2011). Manual de Organização de eventos, planejamentos e operacionalização. São Paulo: Atlas. 